\title{
Innovative Milieu Diagnosis: The Case of the Healthcare System in Saint Petersburg
}

\author{
Alexandra Victorovna Titova \\ Lecturer, faculty of Economics, St. Petersburg State University of Aerospace Instrumentation, Russia \\ E-mail: alexandra_titova@list.ru \\ Irina Gennadievna Golovtsova
}

Professor, PhD, faculty of Economics, St. Petersburg State University of Aerospace Instrumentation, Russia

E-mail: golovtsova@mail.ru

Elena Anatolievna Gorbashko

Professor, vice-rector on quality assurance, PhD, St. Petersburg State University of Economics, Russia

E-mail: egorbash@finec.ru

\section{Doi:10.5901/mjss.2016.v7n4p}

\section{Abstract}

The diagnosis of innovative milieu is the initial step in the creation or modification of the milieu, aimed at providing sufficient information for making management decisions. This paper contributes to theoretical and practical aspects of innovative milieu diagnosis. Innovative milieu is regarded as the subsystem of a territory or industry, composed of the specified actors' properties. In contrast to those commonly applied, the diagnosis method proposed firstly enables the capacity of the milieu to create required and suitable whole system innovations to be evaluated, and secondly, it allows diagnosis of innovative milieu in the initial stage of its formation or even in the preconditions. The designed method is applied to the diagnosis of innovative milieu in the healthcare system of Saint Petersburg.

Keywords: innovation, healthcare system, system requirements, diagnosis, innovative milieu

\section{Introduction}

Innovation has always been considered the lead driver of technological and socio-economic development; however contemporary studies in fields like innovation ethics and many others disagree with such statements. One argument is that there is no need for such great amounts of innovation when quality is unsatisfactory, while others continue to prove that innovative development cannot harm the socio-economic system. There is one very good example of the destructive role of intense innovation: healthcare systems. Most researchers share the view, that «decades of rapid innovation and technological improvement have created an extraordinarily complex health care system. Clinicians and health care staff work tirelessly to care for their patients in an increasingly complex, inefficient, and stressful environment. Certain breakthrough innovations have benefited millions of patients, but the aggregate impact of the flood of new interventions has introduced challenges for both clinicians and patients in treating and managing health conditions» (Smith et al., 2013, p. 49). Synthesis and analysis of information related to the development of healthcare systems, including much research carried out by the IOM (Institute of Medicine, USA), the University of London and Russian scientists, demonstrate the need for the development of new theoretical and methodological approaches to lead the innovation processes taking place in healthcare systems.

The concept of innovative milieu (IM), as proposed by the GREMI (Groupe de Recherche Européen sur les Milieux Innovateurs), seems to be an adequate concept necessary for managing innovative processes, particularly for the interests of patients. A new dimension of the concept, as discovered by the GREMI 6 (Tabaries, 2005), shows its flexibility and proves that IM is an efficient process not only for better exploitation, but also for the preservation of natural, cultural and heritage resources and is applicable not only to the management of technological innovations, but also to social and organisational ones. However, while much has been written about the concept of IM there is no consensus on the definition of it as a notion, its structure, its identification in the system or for the methods of its diagnosis, formation and management. The diagnosis of IM or of a system's preparedness for its formation (i.e. preconditions) is the initial 
stage preceding its creation or moderation.

This paper aims, in a first attempt, to contribute to the theory and methodology of IM diagnosis. Having studied different methods presented in varying publications we found that the methodology of emulation (copying a system's successful experience) was the most common conceptual basis. In this method, diagnosis is based on the evaluation of visible parameters in order to estimate compliance between the managed system and its etalon. Territories and industries vary in a significant number of factors (Maillat, Lecoq, 1992); this makes the transfer of management techniques, as well as etalon states, between systems impossible in most cases. Thus, the diagnosis of IM should be based primarily on the vision of its role in the system. It is necessary to measure the degree of compliance between the present state of IM and its target state, as determined by the requirements of the system.

This article is organised as follows: in the second part we explain the theoretical basis of IM because the interpretations presented in modern economic literature do not give a clear idea of the conceptual element of the notion. In the third part, we propose an algorithm for managing the creation/moderation of IM in accordance with the procedure of creation proposed by one of the authors at a conference with international participation (Titova, 2016). Thirdly, according to the proposed approach, we sum up the requirements of the healthcare system for $I M$, such as requirements for innovation, innovation process models, sources of innovative ideas and development directions. The results of the proposed method and its application to the diagnosis of the Saint Petersburg healthcare system innovative milieu are presented in the fourth section. Finally, we propose practical recommendations for the formation of IM in the Saint Petersburg healthcare system.

\section{Theoretical Basis of the Research}

\subsection{IM conception as the theoretical basis of the research}

The concept of IM was proposed by the GREMI in 1984 (Tabaries, 2005). During the last two or three decades it has gained much popularity among researchers studying the development of socio-economic systems as territories and industries (sectors). As we have already mentioned, despite the popularity and frequent application of this approach, a conceptual theoretical definition of the notion and its structure has not yet been proposed. Having studied papers related to IM we conclude that this uncertainty results from the application of the approach to different territories which exhibit different IM structures. We are interested not in the milieus identified by researchers, but in the theoretical background of the concept.

IM has been defined in different ways: as a set of key success factors, as an ensemble of economic actors and their relationships and as a group of active subjects (Tabaries, 2005). These definitions seem contradictory. The paradox is easily explained by applying a system analysis; the set of factors is regarded as input for IM, whereas the subject's actions (innovations) are regarded as output. So what is necessary to identify is the "middle" of this process - the system that transfers contextual factors into the subject's innovative actions. Having taken into account empirical research conducted by the GREMI since 1984 and theoretical research conducted by the CID (Club of Innovative Development, Lepskii, 2010) since 1960, we propose a conceptual definition of IM.

IM is a self-developed set of specific, consistently agreed upon properties of the subjects (active elements of the studied system) that determine the decisions and actions of the subjects (when they are performing their roles in the system) and directly or indirectly impact on the qualitative and quantitative characteristics of innovation. According to the synthesis of empirical results obtained by the GREMI and the theoretical socio-humane model proposed by CID three main groups of subjects' properties required for the formation of innovative milieu have been identified.

The first group includes properties which determine the coherence of subjects' targets and doctrines (common ways of behaviour to achieve the target) and target the whole system. This group of properties is often leveled during the analysis of IM factors, however it was originally declared by the GREMI to be the key. «Milieu identity and sense of belonging fulfil the important function of harmonizing the agents' differing professional background (...) and interests, directing them towards common goals of locality development» (Fromhold-Eisebith, 2004, p. 750). Thus, it seems necessary to examine, firstly, the agreement of the actors' (while performing their role in the system) and system's goals (expressed in its requirements to the milieu), and secondly, the agreement of the applied doctrines with the goals declared by the actors. For example, innovation as the means of achieving a goal is considered the doctrine that the majority of actors should share. Doctrines determine not only the level of innovativeness, but also the quality of produced innovation; that is, its correspondence with system requirements. Thus, the doctrines of healthcare actors can be identified as "utilisation of innovation", "health promotion priority", "patient-centredness", "evidence-based healthcare" and "active use of information system". 
The second group includes properties that characterise the level of a subject's integration. It is degree of integration that is usually evaluated by economists using indicators such as the concentration of small and medium companies, the strength of partnerships, the degree of horizontal and vertical integration and the level of spill-off (Tödtling, Trippl, 2005; Nauwelaers, Wintjes, 2002). The proposed model of IM regards these properties as providers for the first group, as they ensure the efficiency of resource utilisation rather than the effectiveness of achieving the goal. These properties include links between subjects, belonging to a collective subject and reflection.

The third group includes properties that raise the efficiency of previous properties' utilisation; we call them providers. These features include openness to innovation, the ability to generate ideas, the ability to receive and transmit information, a proactive attitude and so forth.

Thus, it is necessary to determine a general methodology or algorithm of diagnosis, to define the subjects or "wearer" of the properties and to specify the properties required for effective implementation of the actors' roles in the milieu.

\subsection{IM formation and diagnosis of conceptual basis}

The developed method of creation (or modification) of IM in a system involves the designing of the milieu as a subsystem of the healthcare system (i.e. constructed in accordance with the requirements of healthcare), taking into consideration the results of IM and its preconditions diagnosis. In contrast to methods based on the evaluation of contextual factors, the proposed method is founded on the analysis of actors' properties, where context is regarded as an influential factor. The proposed algorithm is presented generally in Figure 1.

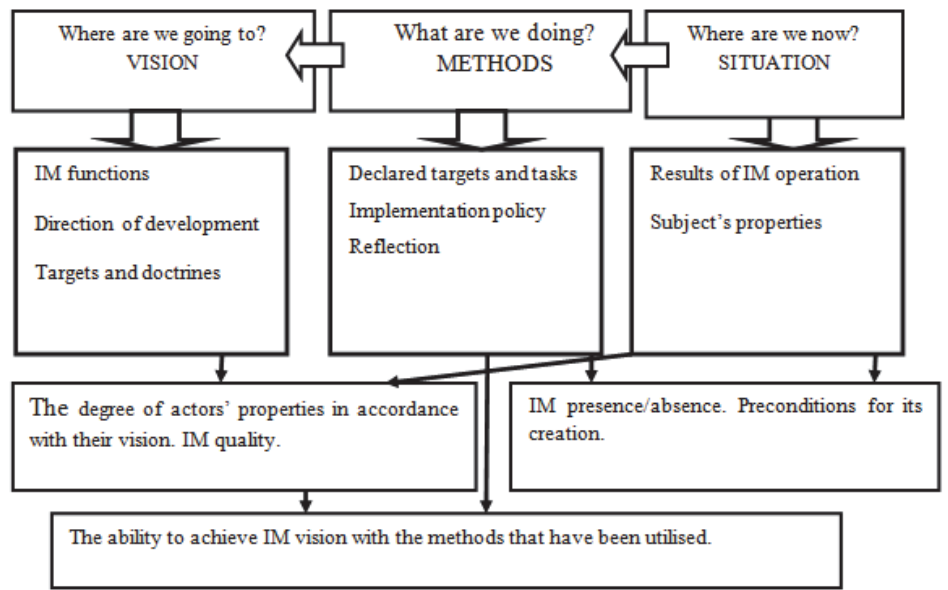

Fig. 1. General algorithm of the diagnosis

The initial step in the proposed algorithm is to determine the vision of IM's role in the system. The vision defines potential IM actors and specifies their properties. Consistent implementation of the algorithm allows the gap between present and target IM actors' properties to be determined in order for the optimum combination of methods to be formed and for the implemented methods and their ability to create IM or conditions for its formation to be evaluated.

\subsection{IM diagnosis indicators' classification}

Indicators applied for IM diagnosis have been classified in accordance with their relation to IM (whether the estimated factor is the result of IM activity or the influential key success factor) and secondly, their relationship with quantitative (innovativeness) and qualitative (quality) characteristics of IM operations. The generalised results of classification are presented in Table 1. 
Table 1. The classification of the indicators applied to IM diagnosis

\begin{tabular}{|c|c|c|}
\hline & Results & Key success factors \\
\hline Innovativeness & $\begin{array}{l}\text { 1. The results of innovative development } \\
\text { - General volume of innovative products } \\
\text { - The share of innovative products } \\
\text { - The amount of patents } \\
\text { - The amount of innovative practices }\end{array}$ & $\begin{array}{l}\text { 2. Integration and density } \\
\text { - The level of SME concentration } \\
\text { - The amount of spill-offs } \\
\text { - The amount of agreements between business } \\
\text { and science } \\
\text { - The degree of easy financing }\end{array}$ \\
\hline Quality & $\begin{array}{l}\text { 3. The suitability of the results to the requirements of } \\
\text { the system } \\
\text { - The volume of innovative products suitable to system } \\
\text { requirements } \\
\text { - The share of suitable products in innovative products } \\
\text { - The share of patents received for suitable production }\end{array}$ & $\begin{array}{l}\text { 4. Coherence properties } \\
\text { - The degree of coherence between actors' and } \\
\text { systems objectives } \\
\text { - The degree of coherence between actors' } \\
\text { doctrines and declared objectives }\end{array}$ \\
\hline
\end{tabular}

The indicators of the first quadrant of the matrix are most currently applied; still it is necessary to understand that their being used while excluding other indicators may cause false inference:

- IM overestimation. This kind of situation can be observed when successful results arise not only from IM operations, but also from other factors, for example, available venture funding.

- IM underestimation. This is most probably seen when IM has just been formed (or is in the process of formation), thus visible results of its operation have not been received. The possibility of this situation has to be reduced.

- Incorrect IM operating leading to the spread of innovation that does not bring advantages to the system, sometimes even bringing harm. This situation is rather common for healthcare systems.

The analysis of innovative activity results is often completed with the analysis of IM success factors (the second quadrant). Typical factors, such as SME concentration, degree of territory diversification/specialisation, amount of agreement among actors and so forth are usually estimated (Tödling, Trippl, 2005; Nauwelaers, Wintjes, 2002), though they ensure the quality of innovation spread rather than the quality of innovation. The analysis of these factors specifies the impact of IM on the total result (quadrant 1). Statistical regression analysis is most currently applied (Maennig, Ölschläger, 2011), although some investigators propose econometric models (Capello, 1999). The use of the second quadrant indicators allows the risk of false inference arising from IM over- or underestimation to be reduced, but does not bring clarity to the understanding of IM operating quality, that is the fidelity of the IM settings.

The third quadrant represents indicators estimating the degree of innovative products' suitability to system requirements. However, while most researchers share the view that the quality and direction of innovative development are of great importance, indicators of this group are rarely calculated. This often arises from the currently applied technology of emulation, when accordance with the etalon but not with the requirements of the system, is necessary.

The indicators of the fourth quadrant have been developed by the authors of this paper. The estimation of these indicators in the initial stage of IM formation is the key success factor in the creation of IM suitable to the requirements of the system. As for the already operating IM, these indicators help to recognise the causes of false IM settings and provide for its moderation.

IM diagnosis, represented in the following sections, is based on the published results and was completed with the results of the research carried out by authors. Due to the impossibility of considering the total volume of our research the empirical section concentrates on the analysis of IM and its preconditions' present state. Thus, the results of the synthesis of the system's requirements are summarised below.

\section{Research into the Healthcare System's Requirements}

Defining healthcare innovation, investigators commonly appeal to innovation in the healthcare delivery system field, but not to the productive sector (pharmacy, medical equipment, etc.) ensuring the operation of healthcare systems. The group of British researchers (Greenhalgh et al., 2004, p. 582) defined «innovation in service delivery and organization as a novel set of behaviors, routines, and ways of working that are directed at improving health outcomes, administrative efficiency, cost effectiveness, or users' experience and that are implemented by planned and coordinated actions». Many researchers appeal to the definition proposed by the American investigators Thakur, Sonya и Fontenot (2012, p. 564): 
«Healthcare innovation is defined as adoption of those best-demonstrated practices that have been proven to be successful and implementation of those practices while ensuring the safety and best outcomes for patients and whose adoption might also affect the performance of the organization. In other words, innovation in healthcare is defined as those changes that help healthcare practitioners focus on the patient by helping healthcare professionals work smarter, faster, better and more cost effectively».

In terms of common definitions, medical organisations and medical personnel are considered the main actors of innovative processes in the healthcare system. For investigators carrying out research on basically market-regulated healthcare systems (Thakur, Sonya и Fontenot, 2012) or on its commercial sector (Meroño-Cerdan, López-Nicolas, 2013) it is typical to regard companies as the main innovation drivers; whereas this group of researchers give the honour to medical practitioners as self-dependent actors of the innovative development common in government regulated healthcare systems and widespread GPs (General Practioneers) (Dopson, Fitzgerald, Ferlie, 2008).

Healthcare delivery practice and information exchange are frequently regarded as sources of ideas for healthcare innovation. For example, «a study conducted by Marceau in the late 1990s in New South Wales showed that in the great majority of cases, the idea for a new medical device came from the potential users, the surgeons working in major hospitals, who often sketched the ideas literally on the back of an envelope» (Marceau, 2001, p. 298-299).

Healthcare system research (HSR) appears to be an inefficient source of innovative ideas. Having assumed HSR to be a poor source of innovative ideas on the one hand and a peculiar filter (by providing evidence) on the other, many countries have taken different actions to intensify research activity in this field. Nevertheless, Canadian researchers Graham, Tetroe (2007, p. 20) notice: «despite the billions spent annually on health research around the world and the roughly $\$ 700$ million spent by $\mathrm{CIHR}$ on high-quality health research, a consistent finding from the literature is that the transfer of research findings into practice is often a slow and haphazard process». Thus, the R\&D (research and development) innovative process model does not always provide for useful, valuable products and services and usually becomes an inefficient way to produce healthcare innovation.

An empirical study of service innovation carried out by Finnish researchers shows that models of rapid application and practice-driven models are the most commonly used, also proving efficient in service organisations. «In the practicedriven model, the service is developed step by step together with the client, and the observation of a significant renewal is made only afterwards. After the recognition of the innovation, its further development may be done systematically, as in the case of rapid application» (Toivonen, Tuominen, 2009, p.898).

It is also necessary to determine the main creation and diffusion directions of healthcare innovations, which further define actors' doctrines. Many researchers (Thakur et al., 2012; Verwey, Crystal, 1998; Sackett et al., 2000; Lipp, 2003; Smith et al., 2013) share the opinion that such directions are:

- the development of preventive care and health promotion;

- the development of patient-centered approaches;

- the development of evidence-based medicine and evidence-based healthcare;

- the active use of information systems.

\section{Methodology}

\subsection{Purpose of research}

The empirical research concentrates on the diagnosis of the IM present state and preconditions for its formation. Methodology of the research presented in the paper was driven by three goals: (1) to determine the fact of IM presence or absence in the system, (2) to estimate preconditions for its formation, (3) to estimate the degree of coherence between actors' properties and system requirements according to IM model proposed in the paper.

\subsection{Data sources}

Primary data includes the results of the survey that took place in Saint-Petersburg in 2015. It consisted of 80 semistructured interviews hold with physicians practioneers. Firstly, a stratified sample of clinics based on the form of property ownership, level of specialisation and size was drawn to provide the coverage of practioneers from different types of medical organisations. A total of twenty two clinics were chosen for the survey. Then, the amount of interviews in each clinic was determined in straight ratio to its size and eighty physicians were randomly chosen using clinic's data base. The respond rate was $96 \%$ due to the support of the top management. Standard error for $95 \%$ confidence interval for the sample is not higher than $4,3 \%$. 


\subsection{Methods and procedure of research}

The questionnaire included 55 items for quantitative estimation and several questions for the discussion (5-8 open questions). In-depth questions were related mainly to specific motives and barriers that determine doctrine's utilization. Physicians were asked about their targets, the doctrines they apply, specific use of contacts and partnerships, different sources of information, barriers they face, support they receive and so forth.

In order to evaluate actors' properties for the proposed IM model quantitatively several types of questions were used. The questions were aimed at measuring socio-demographic characteristics; results of the diffusion and application of innovation; behavioral characteristics (objectives, doctrines); integration properties (ways of integration, its frequency); properties-providers for previous (willingness and preparedness for innovation, the degree of activity, communicativeness). The average duration of each interview was 30 minutes.

Interviewers were trained by authors in order to carry out an integrated information collection procedure: data were filtered and recorded as soon as information was received. Interviews were taped by researchers and listened by authors in order to discover new categories, tendencies, directions for future development. For quantitative data analysis statistical methods were used: descriptive statistics, frequency and cross-tabulation analysis.

\section{The Results of the IM Diagnosis}

\subsection{The results of innovative development}

Although the majority of Russian and foreign researchers cannot find significant evidence of innovative activity in Russian regional healthcare systems we appended several questions assessing the intensity of innovative development. We must also note that organisational and social innovations are not reflected in governmental statistics; thereby they could not be a part of the analysis. The results, received on completion of our research, confirmed the absence of innovation in the healthcare system. Seventy-six per cent noted no significant changes in service delivery practice and workplace organisation (excluding the implementation of information systems). Eight per cent of clinicians referred to the changes occurring as significant. They said they synthesise information from different sources, including their own practice, and applied this new knowledge to their service.

\subsection{The study of actors' properties}

\subsubsection{Coherence properties}

A broad range of experts share the opinion that recovery and rehabilitation, not health preservation, should be a physician's main objective. The results of the conducted survey show that the majority of respondents (96\%) pay attention to the prevention of diseases and health promotion, but much time is still spent on diagnostics and treatment (only $10 \%$ of respondents estimate the time spent on preventive care to be more than $30 \%$ of total work time). The majority of physicians (74\%) believe they do not have enough influence over patients to make them change habitual behaviours. The majority of patients go on leading their customary life, correcting it just a little and usually for a short while; this is a most unfavorable fact. One reason for this situation identified by respondents is the lack of specified experience, tacit knowledge and know-how; they are not taught this in university. Physicians are trying to persuade their patients to lead a healthy life, and they agree, but next time they come with the same problems arising for the same reasons (semi-structured interview results). The physicians that are able to persuade their patients specify that they do not know how it happens. Specific practices which are utilised to reform patients' lifestyles show much in common with the ad hoc innovation proposed by Gallouj and Weinstein (1997), but in terms of commonly mentioned innovation attributes they have to be not only effective, but also replicable. Thus, it must be possible to identify the main components of the practice and diffuse them further, that is, to use a practice-driven model of innovative process. This has to be ensured by specified knowledge and doctrines. Thus, the absence of motivation for providing preventive care, as pointed out in programs of healthcare modernisation, is not the main barrier to the development of preventive care.

As for evidence-based practice, physicians pointed out several barriers to their uptake: lack of time (pointed out by $87 \%$ of respondents) and lack of access to information on the latest research from the workplace (85\% respondents). It is necessary to note that, in countries where the problems mentioned above are solved, physicians refer frequently to their lack of skills in knowing how to use evidence to inform their practice, doubts about the transferability of evidence across contexts, difficulties in interpreting technical/academic language and jargon, little relevance to their practice given the high 
cost of implementing the interventions cited, and so forth (Armstrong et al., 2007). Thus, providing easy access to information and sufficient time are not going to solve the problems of using evidence-based medicine.

As for results showing the use of a patient-centered approach we notice that Russian clinicians perform well: $70 \%$ remember their patients when face to face, $60 \%$ take their patients' opinions into account when appointing a treatment and $40 \%$ pointed out that their amount of diagnostic testing has reduced due to successful contact with their patients. The physicians could not determine the reasons for the efficiency of their relationships with patients: the majority of respondents (68\%) consider the possibility and success of such relationships to arise from a patient's peculiarities.

\subsubsection{Integration and density properties}

Physician milieu is characterised by a high degree of integration and density. The clinicians have good relationships with colleagues, not only in their present place of work, but also from previous workplaces and from university; they communicate at work and at conferences, and in social networks they discuss interesting clinical cases, service delivery practice, new medicine and treatment methods, but they rarely discuss changes occurring at medical organisations.

\subsubsection{Properties of providers}

The results of estimation of third level properties show that clinicians are open to new knowledge and experience, are ready to engage in new practices and are willing to continue permanent education and self-development. Some physicians pointed out their lack of money and time, but these factors have not become barriers. Sixty-eight per cent said that if their revenue grew in proportion to their level of knowledge and experience they would be more willing to study and self-develop. Fifty-two per cent declared a lack of time for gaining new knowledge and experience.

\subsubsection{Findings}

Despite thick integration, strong relationships, willingness to engage in new practices and readiness for moving toward patient's needs, the distinguishing, diffusion and implementation of innovations is very poor. The absence or insufficiency of physician motivation, noted by many researchers as the main reason for inability to innovate, does not seem to be the primary influential factor. The absence of tacit knowledge and special skills required to innovate toward practice-driven models (the ability to find an innovative idea, identify its constituents and transfer and diffuse the decision) has become the main barrier to effective healthcare innovation.

\section{Conclusion}

The diagnosis of IM presented in this paper shows that despite common opinion on the necessity of intensifying horizontal links of informal communication and partnerships, of forming communicative clubs and professional networks and of stimulating healthcare staff the development of innovative milieu requires other methods to be performed successfully. Thus, physicians are not poorly motivated in key doctrines (preventive care, health promotion, patientcentredness, evidence-based healthcare) but they do not possess the required practices and methods necessary to perform them efficiently. The stimulation and motivation of clinicians should take a backseat to the implementation of specific methods to help clinicians to develop tacit knowledge. Shchedrovitskii, Russian scientist outlines: "this kind of methodology could not be transmitted, like knowledge or a set of instruments, from one person to another, but rather could only evolve, grow out of a context, as it were, through people's being brought into a sphere of methodological thinking activity that was new for them, but in which they were given the opportunity to participate in a complete and integral vital activity» (1988). At present, the methodology of organisational activity games, as proposed by the CID, is the most suitable means to achieving this vision.

\section{References}

Armstrong, R., Waters, E., Crockett, B., Keleher, H. (2007). The nature of evidence resources and knowledge translation for health promotion practitioners. Health Promotion International, 22:3, 254-260.

Capello, R. (1999). SME Clustering and factor productivity: A milieu production function model. European Planning Studies, 7:6, 719735 .

Dopson, S., Fitzgerald, L., Ferlie, E. (2008). Understanding Change and Innovation in Healthcare Settings: Reconceptualizing the Active 
Role of Context. Journal of Change Management, 8:3-4, 213-231.

Fromhold-Eisebith, M. (2004). Innovative Milieu and Social Capital-Complementary or Redundant Concepts of Collaboration-based Regional Development? European Planning Studies, 12:6, 747-765.

Gallouj, F., Weinstein, O. (1997). Innovation in services. Research Policy, 26:4-5, 537-556.

Graham, I.D., Tetroe, J. (2007). How to translate health research knowledge into effective healthcare action. Healthcare Quarterly, 10:3, 20-22.

Greenhalgh, T., Robert, G., Macfarlane, F., Bate, P., Kyriakidou, O. (2004). Diffusion of innovations in service organizations: systematic review and recommendations. The Milbank Quarterly, 82:4, 581-629.

Lepskii, V.E. (2010). The reflexion-activity milieux of innovative development. Moscow: Kogito-center.

Lipp, A. (2003). Liberating clinical effectiveness: A model for consideration. Contemporary Nurse, 15:1-2, 70-80.

Maennig, W., Ölschläger, M. (2011). Innovative Milieux and Regional Competitiveness: The Role of Associations and Chambers of Commerce and Industry in Germany. Regional Studies, 45:4, 441-452.

Maillat, D., Lecoq, B. (1992). New technologies and transformation of regional structures in Europe: The role of the milieu, Entrepreneurship \& Regional Development. An International Journal, 4:1, 1-20.

Marceau, J., Basri, E. (2001). Translation of innovation systems into industrial policy: the Healthcare sector in Australia. Industry and Innovation, 8:3, 291-308.

Meroño-Cerdan, A.L., López-Nicolas, C. (2013). Understanding the drivers of organizational innovations. The Service Industries Journal, 33:13-14, 1312-1325.

Nauwelaers, C., Wintjes, R. (2002). Innovating SMEs and Regions: The Need for Policy Intelligence and Interactive Policies. Technology Analysis \& Strategic Management, 14:2, 201-215.

Sackett, D., Straus, S., Richardson,W. S., Rosenberg,W. and Haynes, R. B. (2000). How to Practice and Teach Evidence-Based Medicine. London: Chuchill Livingstone.

Shchedrovitskii, G.P. and Kotel'nikov, S.I. (1988). Organisational activity games - a new way of organising and a method for developing collective thinking activity. [Online] Available: http://www.fondgp.ru/gp/biblio/eng/12 (March, 15, 2016).

Smith, M., Saunders, R., Stuckhardt, L., McGinnis, J.M. (2013). Best care at lower cost: the path to continuously learning health care in America. Committee on the Learning Health Care System in America, The Institute of Medicine. Washington, D.C.: The national academies press.

Tabaries, M., (2005). Les apports du GREMI à l'analyse territoriale de l'innovation ou 20 ans de recherche sur les milieux innovateurs. [Online] Available: http://mse.univ-paris1.fr/MSEFramCahier2005.htm (March, 15, 2016).

Thakur, R., Sonya, H.Y., Fontenot G. (2012). Innovation in healthcare: Issues and future trends. Journal of Business Research, 65, 562569 .

Titova, A. (2016). The possibility of applying foreign experience for the formation of innovative development technology. Materials of the scientific-practical conference with international participation "Strategic management of organizations in the XXI century", St.Petersburg Polytechnic University, 103-118.

Toivonen, M., Tuominen, T. (2009). Emergence of innovations in services. The Service Industries Journal, 29:7, 887-902.

Tödtling, F., Trippl, M. (2005). One size fits all? Towards a differentiated regional innovation policy approach. Research Policy, 34, 1203-1219.

Verwey, S., Crystal, A. (1998). A patient-centred approach to health care: the role of health communication. Communicatio: South African Journal for Communication. Theory and Research, 24:2, 31-42. 